class. Master's departments in turn hired a relatively small proportion of the group-dropping from about $16 \%$ of the class in the last several years to just $11 \%$. Undergraduate school $(31 \%)$, two-year school $(2 \%)$, and nonacademic $(10 \%)$ proportions remained about the same.

For the first time, the survey showed a strong gender difference in placement by institution, however, with a much larger share of men in the placement class joining Ph.D. level institutions than of women. Almost half of the men in the class, $48 \%$, were hired by Ph.D. granting schools, compared to $39 \%$ of the women. Women, in turn, were slightly more likely to be hired by M.A. and undergraduate degree granting schools.

\section{Minority Placement}

There were 38 African-American students in the placement class and 26 Latinos, a continued increase in numbers over previous classes. The 1990 placement class included 36 African-American and 21 Latino candidates. Placement of AfricanAmerican candidates mirrored the class as a whole $-74 \%$ found positions.

Placement of Latino students improved dramatically over that of two years ago. This year, almost all of the Latino candidates in the class, $88 \%$, found positions. Two years ago, just half of the Latino candidates had been placed.

Of 29 Asian-American candidates in the placement class, just $62 \%$ were placed this year. However, placement of those Asian-American candidates with the Ph.D. in hand was at the $80 \%$ rate.

\section{Jobs in Political Science}

Overall, the AY 1991-92 placement class in political science has had a relatively successful year, allaying concerns about a possibly lackluster job market. This is especially encouraging since this placement class entered the market in a year in which actual job listings, as identified in the APSA Personnel Service Newsletter, had shown a significant drop from previous years-down by $18 \%$ from 1989-91 levels when listings had been unusually strong.
There are conflicting signals for the 1992-93 placement class. Numbers of political science openings reported in the Personnel Service Newsletter have remained steady since 1991-92, suggesting that new placement classes should expect similar experiences to the 1991-92 class described here. However, the Departmental Survey reports of expected hires do show a drop-off among Ph.D. institutions, where hiring for the 1991-92 class was strong. In the meantime, over one-third $(37 \%)$ of the graduate programs report they expect their placement class to be larger this year than last; only $8 \%$ expect the class to be smaller. Together, these developments may result in a tighter job market for new graduates than we saw in 1991-92.

\section{Washington Restaurants: Annual Meeting Dining Guide}

\section{Diana Falls}

One of the most enjoyable aspects of visiting Washington, D.C. is sampling the many fantastic and diverse restaurants. Diners can enjoy a superb selection of international cuisine to please anyone's palatefrom French, Italian, and Indian to Mexican, Ethiopian, American, and Thai. The following restaurants are highly recommended and are all within walking distance from the Washington Hilton \& Towers, Sheraton and Omni-Shoreham. This list is by no means inclusive and diners will no doubt have luck finding a cozy restaurant on their own if they do a bit of window-shopping. We have begun the list with restaurants in the Dupont Circle area, but for the more adventurous diner, Adams Morgan is just around the corner where virtually any cuisine can be tasted.

The cost of dinner for two, including cocktail, appetizer, entree plus tax and $15 \%$ tip is the basis for the following scale: $\$ 40$ or less, $\$$; $\$ 41-75, \$ \$ ; \$ 76-140, \$ \$ \$$; and more than $\$ 140, \$ \$ \$ \$$. Bon Appetit!

\section{DUPONT CIRCLE}

Vincenzo, 1606 20th St., NW. Hours: M-F noon-2pm, 6:30-9:30pm; Sat $6-10 \mathrm{pm}$. Authentic Italian cuisine whose specials include fettuccine Alfredo, linguine and clam sauce, and lamb stew. $\$ \$ \$$

Donna Adele, 2100 P St., NW. Hours: M-Th 11:30am-2:30pm, 5:3010:30pm; F-Sat 5:30-11 pm; Sun 5:309:30pm. New menus drawn up daily, such as plump ravioli with eggplant stuffing and red snapper presented on a bed of black olives and sliced artichoke bottoms. Reservations. \$\$

Lucie, 2015 Massachusetts Ave., NW. Hours: M-Sat 11:30am-2pm; 6-10pm; Sun 11:30-2:30, 6-9:30pm. Nouvelle cuisine featuring miniature salads and small custards. Reservations. $\$ \$ \$ \$$

Obelisk, 2029 P St., NW. Hours: M-Sat 6-10pm. Italian cuisine. Offers a fixed price of $\$ 33$, enjoy four- or five-course menus with choice of cheese or dessert or both. $\$ \$ \$$

Pizzeria Paradiso, 2029 P St., NW. Hours: M-Th 11am-11pm; F-Sat 11 am-midnight; Sun noon-10pm. A must visit for pizza lovers, offering authentic style crusts with unusual toppings. $\$$

Cafe Luna, 1633 P St., NW. Hours: M-Th 8am-11:30pm; F 8am-2am; Sat 10am-2am; Sun 10am-11:30pm. Italian cuisine. Voted "50 Best Values" in Washington Post. Featuring fresh pasta, pizza and salads. Great cappuccino and desserts. \$

City Lights of China, 1731 Connecticut Ave., NW. Hours: M-Th 11:30am-10:30pm; F 11:30-11pm; Sat noon-11 pm; Sun noon-10:30pm. Featuring Hunan style Northern Chinese cuisine in a cozy atmosphere. $\$$

Joe and Moe's Restaurant, 1211 Connecticut Ave., NW. Hours: M-F 7:30am-10:30pm; Sat 6pm-1 am (big band dancing). World famous steak and seafood house/nightclub. American cuisine with menus available in Spanish, French, Japanese, Arabic, and German. $\$ \$ \$$

Kramerbooks \& Afterwords Cafe, 1517 Connecticut Ave., NW. Hours: Sun-Th 7:30am-1am; 24 hours F-Sat. Full-service restaurant featuring fresh 
fish, pastas, salads from around the world. Browse in the bookstore while waiting. $\$ \$$

La Tomate, 1701 Connecticut Ave., NW., (202) 667-5505. Featuring excellent Italian cuisine in a romantic, charming setting on the corner of Connecticut. Reservations. \$\$-\$\$

Odeon Cafe, 1714 Connecticut Ave., NW. Hours: M-F 11:30am-midnight; Sat 5pm-midnight; Sun 5pm-10:30 pm. Charming Italian restaurant featuring a huge selection of all the traditional favorites. Diners will enjoy their meals on a large balcony overlooking the art deco bar and main dining room. $\$$

Pan Asian Restaurant, 2020 P St., NW. Hours: Sun-Th 11:30am-10pm; F-Sat 11:30am-11 pm. Highly recommended by several local dining critics, featuring distinctive Asian cuisine. Reservations suggested. $\$$

Sam \& Harry's, 1200 19th St., NW. Hours: M-F 11:30am-11pm; Sat $5: 30-11 \mathrm{pm}$. The Washington Post exclaims, "Here is the steak that made America great!" Also featuring fresh fish, lobster and prime chops set in a comfortable dining room with full bar. Live jazz nightly from 8:30 to midnight, Sat 9-1 am. Reservation, coat and tie. $\$ \$ \$$

Sushi Taro, 1503 17th St., NW. Hours: M-Th 11:30-2pm, 5:30$10 \mathrm{pm}$; F-Sat 11-2 pm, 5:3010:30; Sun 5:30-10pm. Traditional Japanese style dishes served with steamed rice and choice of sauces. Reservations. \$\$

Taj Mahal Restaurant, 1327 Connecticut Ave., NW. Hours: M-F 11:30 am-2:30pm, 5:30pm-10pm; Sat-Sun 5:30-10pm. Washington's oldest Indian restaurant, recommended by both the Washingtonian and Washington Post. Reservations. \$

\section{ADAMS MORGAN}

I Matti, 2436 18th St., NW. Hours: M-Th noon-11pm; F-Sat noon-11:30 pm. The pastas and main courses are models of Italian simplicity emphasizing the individual flavors. The menu offers a variety of foods, from soups and pastas, to appetizers and substantial entrees. Reservations. \$\$

Grill from Ipanema, 1858 Columbia Rd., NW. Hours: M-Th 5pm-11pm;
F 11:30; Sat-Sun noon-11pm. Offering a wide variety of seafood dishes, including peppery conch chowder and cherrystone clams, stylized in a uniquely modern setting. $\$ \$$

Star of Siam, 2446 18th St., NW. Hours: M-Sat 11:30am-11pm; Sun 4-10pm. Excellent Thai food in a traditional setting with large chairshaped cushions adorned with glittering embroidery. Newcomers should try a sampling of the Thai curries, including curry with beef, red curry with fish and green curry with chicken. $\$$

Cafe Dallol, 2226 18th St., NW. Hours: Sun-Th 11 am-2am; F-Sat $11 \mathrm{am}-3 \mathrm{am}$. Serving a wide variety of Ethiopian cuisine, including chicken, beef, lamb, and vegetarian dishes.

Only restaurant in the area serving Teff Injera (real Ethiopian bread). Reservations. \$

Millie \& Al's, 2440 18th St., NW. Hours: Sun-Th 4pm-2am; F-Sat noon-2am. Perfect place for pizza, beer and a lively atmosphere. A favorite of the locals. $\$$

Veneziano Restaurant, 2305 18th St., NW. Hours: M-Sat 11:30am-2:30pm, 5:30-11:30pm; Sun 5:30pm-11:30pm. Italian cuisine set in a casual trattoria ristorant serving home-made pasta, risotti, rabbit, and much more. Reservations. \$

Fish, Wings \& T'ings, 2418 18th St., NW. Hours: M-Th noon-10pm; F-Sat noon-11pm. Wonderful thematic atmosphere makes you feel as if you are dining in Jamaica, with its colorfully painted tables and oversized kitchen stools. Everything is equally good and inexpensive, but don't pass up the fiery curry wings! \$

Lauriol Plaza, 1801 18th St., NW. Hours: M-Sat noon-midnight; Sun 11 am-midnight (brunch until 3pm). A wonderful combination of Spanish and Mexican specialties with great outdoor seating. If you enjoy margaritas, be sure to try a slightly different version of pisco sours. $\$$

La Fourchette, 2429 18th St., NW. Hours: M-Sat 11:30am-11pm; Sun 4-10:30pm. Wonderful French restaurant serving salmon, swordfish, duck and veal in interesting sauces that change daily. Reservations. $\$ \$$

Meskerem, 2434 18th St., NW.
Hours: 7 days a week noon-midnight. Winner of the Washington's "Very Best Restaurant Award," serving Ethiopian cuisine in authentic setting. Generous portions in a festive atmosphere. \$-\$\$

Belmont Kitchen, 2400 18th St., NW. Hours: M 5:30-10pm; T-F 11:30-2:30, 5:30-10pm; Sat-Sun 11:30-3:30 (brunch), 5:30-11:30pm. New American cuisine-specials include upside down pizzas, Kansas City ribs, and big salads. $\$ \$$

Cities, 2424 18th St., NW. Hours: Sun 11:30-9:30pm; M-Th 5:30-2am; F 5pm-3am; Sat 2pm-3am. Featuring Los Angeles cuisine including such entrees as tuna tempura, fried calamari and lemon linguine with lobster. Full bar, good happy hour and night life. $\$ \$$

Cafe Lautrec, 2431 18th St., NW. Hours: 5pm-2am; F-Sat 5pm-3am. Featuring a combination of French and continental cuisine, with entrees such as chateaubriand, shrimp and scallops provencal and many seafood dishes. Reservations. \$\$-\$\$

Red Sea, 2463 18th St., NW. Hours: $11 \mathrm{am}-11 \mathrm{pm}$. One of the many Ethiopian restaurants in the area, serving traditional dishes in authentic setting. A favorite of the locals. \$

El Caribe, 1828 Columbia Rd., NW. Hours: M-Th 11:30am-10pm; F 11:30am-11 pm; Sat noon-11:30pm; Sun noon-10pm. Excellent food with excellent service, specializing in wonderful casseroles of chicken and lamb, beef and seafood. Reservations. $\$ \$$

La Plaza, 1847 Columbia Rd., NW. Hours: 7 days a week, $11 \mathrm{am}-11 \mathrm{pm}$. The sister restaurant to Lauriol Plaza (listed above), specializing in Mexican and Spanish cuisine. Lovely terrace dining. $\$$

Cafe Atlantico, 1819 Columbia Rd., NW. Hours: Sun-Th 5:30pm-11pm; F-Sat 5:30pm-12:30am. Casual atmosphere serving traditional Caribbean dishes such as shrimp and potato croquettes, yucca fritters, curry of lamb, and octopus fricasseed in red wine. Reservations. \$\$ 